\title{
Automatic Dependent Surveillance-Broadcast Training: Does it exist in Collegiate Aviation?
}

\author{
Andrew Leonard \\ South Dakota State University
}

\begin{abstract}
One of the key elements to NextGen is the transition from the current ground- based radar monitoring system to a satellite-based system using the Automatic Dependent Surveillance-Broadcast System (ADS-B). The FAA has set a mandate which requires all aircraft to be ADS-B equipped by the year 2020 in order to continue operating in the National Airspace System. However, the FAA has not set forth any training requirements for aviation instructors or designated examiners. This study looked at how ADS-B is currently being taught among aviation educators across the United States and how important this training is to current aviation curriculum. With the information collected, it was determined that only a minimal amount of ADS-B training is currently taking place across the country, and the training that is taking place is non-standardized and limited due to the perception that ADS-B is only to be used as a traffic advisory tool. There was significant difference in the perceived importance of ADS-B, $t(73)=-2.79, p<.01$ between the flight instructor group and the group containing mostly professors and administrators. Also, a significant difference was found in the comparison of perceived importance and institution, $t(73)=-3.11, p<.01$. There was no significance found when comparing the perceived importance of ADS-B training to the number of years a respondent had worked as an aviation educator, $F(1,73)=.44, p=.508$ or the number of hours a respondent had received ADS-B training, $F(1,60)=.15, p=.699$. There was also no significant difference in the perceived importance of ADS-B training dependent upon if participants operated in a geographic location that had ADS-B coverage, $t(73)=-1.88$, $p=.063$. Several factors were discovered as to why there seems to be no current urgency among aviation educators to train their students in this new technology. In addition, recommended steps the FAA could take in order to help aviation educators with the ADS-B training process were suggested.
\end{abstract}

\section{Introduction}

As the number of flights across the U.S. grows, the current system is causing traffic delays in order to maintain high levels of safety. The Federal Aviation Administration (FAA) estimates that by 2025, the U.S. will average over 128,000 flights per day (FAA, 2010). If a fundamental change to our current system does not occur, the U.S. could see large-scale gridlock in the sky that could cost the U.S. economy $\$ 22$ billion annually (FAA, 2010).

The current solution is the FAA's Next Generation Air Transportation System (NextGen). NextGen represents a large-scale redesign of the National Airspace System (NAS), including upgrades in safety, environmental performance, and airport infrastructure (FAA, 2012). The most critical aspect of the NextGen plan is transitioning our air traffic control ground-based radar system to a satellite-based system that will 
allow pilots and controllers to have access to and share all available information. With this transition from the current ground-based radar system to the satellite-based system, pilots will need to train in new technology such as ADS-B. Currently, however, there are no stated training requirements or proposed training lists for instructors or FAA examiners to determine if a student has adequate ADS-B knowledge.

\section{Background Information and Review of Literature}

Over the last few decades, computer technology advancement has led to sophisticated flight deck technology (Young \& Fanjoy, 2003). Global Positioning Systems (GPS), Glass Cockpits, Flight Automation, and now ADS-B are giving pilots more information and tools to use than ever before. However, as Technically Advanced Aircraft (TAA) have been integrated into the general aviation population, one of the key issues is informing pilots how to take advantage of the increased safety opportunities that are available (Dornan, Beckman, Gossett, \& Craig, 2005). Part of this inquiry into training was caused by an observed increase in fatal accidents in TAA at a time when it was expected that new technology should be causing a decrease in fatal accidents (Fiduccia et al., 2003).

A study of four-year collegiate aviation programs suggested that elements of glass cockpit technology, in some cases, received little or no consideration within the institutions' flight-training curriculums (Young \& Fanjoy, 2002). The study also found that, due to the cost of acquiring appropriate instructional materials, a number of college aviation departments had decided that the responsibility for this advanced training more appropriately belonged with the employing airlines (Young \& Fanjoy, 2002).

Several government institutions and universities agreed to investigate how flight training needed to adapt for TAA. One of these teams, the General Aviation Joint Steering Committee (GAJSC), suggested that the current training format in the general aviation industry was insufficient to exploit the additional safety features of TAA's, and that there was a need to develop a specific TAA training program (Fiduccia et al., 2003).

The purpose of this study was to see what level of ADS-B training was currently taking place in collegiate aviation institutions, and whether the perceived value of ADS-B training was significantly different between aviation educators who provided ADS-B training and those educators who did not provide ADS-B training. It also looked at the types of media and methods some institutions were currently using to teach ADS-B information, and whether more specific training requirements from the FAA would help to increase the efficiency of ADS-B training.

\section{Methodology}

\section{Participants}

The sample for this study consisted of aviation educators working in four-year colleges and universities who were members of the University Aviation Association. In order to keep the sample size at a reasonable number, only those members listed in the 
University Aviation Association's Collegiate Aviation Guide (2008) who offered flight/pilot programs were considered. Following these criteria, the sample for the study was 85 educators from various aviation institutions around the country.

\section{Materials}

The survey tool and methodology was adapted with permission from the study completed by Young and Fanjoy (2002). Their study examined how glass cockpit training was being addressed in collegiate flight programs and contained numerous similarities to this study. In 2002, glass cockpit aircraft were considered a new technology, and many aviation educators were in the beginning stages of trying to implement these systems into their training. Today, glass cockpits are more common in aviation training while ADS-B is considered new technology.

\section{Procedures}

To collect data for this study, emails with a link to an electronic survey were sent to individuals listed as the point of contact in the University Aviation Association's Collegiate Aviation Guide (2008). These individuals were asked to forward the survey link on to any educators working directly with students in their pilot training programs. Due to the recent addition of ADS-B, it might have been ineffective to try to target only one particular person within each institution, so opening the survey to all educators within the institutions allowed for the largest amount of useable data. This group was called the "General Sample."

A separate email was also sent directly to Chief Flight Instructors at two aviation institutions that have ADS-B coverage and the majority of their aircraft equipped with ADS-B. The Chief Instructors were asked to send the email and survey directly to their flight instructors. The survey they received was identical to the survey sent out to other points of contact; however, the data was tabulated separately. This response group was referred to as the "Flight Instructor Sample."

Based on previous research, it was expected that because of their size, there would be a higher response rate from these two particular institutions than other institutions surveyed (FAA, 2010). There was a fear that the data could become skewed, showing that a significant amount of aviation educators currently had and were using ADS-B, when research suggested otherwise. By separating the data of these two institutions, the study gained a more accurate picture of current ADS-B use while having the ability to make comparisons between the two groups.

\section{Results}

Fifty-six (65.8\%) of the participants were line flight instructors, 17 (20\%) were chief flight instructors or managers, $6(7 \%)$ were department chairs or directors, and $6(7 \%)$ were professors. The mean number of years the participants had worked as aviation educators was 5.11 with the maximum number of years being 35 and the minimum number of years being less than 1 . 
When asked about the current state of ADS-B coverage in the participants' geographic areas, $61(71.8 \%)$ stated they had ADS-B coverage while $14(16.5 \%)$ stated they did not have coverage; 10 of the participants did not answer the question. When broken down further, $13.3 \%$ from the general survey stated that they had ADS-B coverage in their regions while $66.6 \%$ stated they did not have coverage; $20 \%$ chose not to respond. The total sample reported that $78.49 \%$ of the aircraft used for training at the participants' institutions were equipped with ADS-B hardware, but the general survey reported only $6.25 \%$ of the aircraft were equipped with ADS-B hardware.

Subjects were asked how many hours of ADS-B training their students received. The mean was 19.63 hours with the maximum being 200 and the minimum being .5. Three outliers of 30, 190, and 200 existed, but with the outliers removed from the data, the mean dropped to 3.06 hours. Subjects were also asked to report how many hours of training they themselves had received. The mean for this question was 35.88 hours with the maximum being 1400 and the minimum being 0. Again, with this analysis we saw outliers of $1400,450,270$, and 100 . With the outliers removed, the mean dropped to 1.8 hours.

Educators were asked if the institutions they worked for were currently teaching anything about ADS-B. $50(58.82 \%)$ responded that ADS-B was being taught while 25 $(29.41 \%)$ reported that ADS-B was not being taught at all; $10(11.76 \%)$ did not respond. When looking at the general survey responses, $5(33.33 \%)$ responded that there was some sort of ADS-B training taking place while $7(46.66 \%)$ reported that no training was taking place. In this group, $3(20 \%)$ chose not to respond. Of the educators who said training was currently taking place in their institutions, 11 (22\%) said the training was happening in flight, $8(16 \%)$ said it was taking place in ground school, and $22(44 \%)$ said the training was taking place in both ground school and in the flight training; $9(18 \%)$ did not answer.

The educators who stated their institutions did not currently teach ADS-B to their students were asked if they planned to teach it in the near future. Qualitatively, two themes emerged from this question: (a) respondents felt that there were no current formal plans to start teaching ADS-B in the future and (b) respondents did not know if their institution had plans to start teaching this technology in the near future.

Subjects were asked to rate how effective different media and methods were in trying to educate students about ADS-B. The subjects had the option to rate five different training methods on a five-point scale, with 1 representing "Very Effective" and 5 representing "Not Effective." Subjects also had the option to choose "Not Applicable." The greatest response for effective training material was in "Training Aircraft" with 35, followed by "Lecture" with 31, "Internet" with 28, "Flight Simulator" with 19, and "Video" with 18. The highest percentage of effectiveness was seen in "Training Aircraft," which had a mean score of 1.57. The lowest percentage of effectiveness was seen in "Lecture," which had a mean score of 3.00. 
Table 1

Effectiveness of Training

\begin{tabular}{llllll}
\hline $\begin{array}{l}\text { Training } \\
\text { Option }\end{array}$ & Lecture & Video & Internet & Simulator & Aircraft \\
\hline Very Effective & $2(6.45 \%)$ & $2(11.11 \%)$ & $3(10.72 \%)$ & $5(26.32 \%)$ & $22(62.86 \%)$ \\
Between & $2(6.45 \%)$ & $9(50 \%)$ & $7(25 \%)$ & $7(36.84 \%)$ & $8(22.86 \%)$ \\
Effective & $23(74.2 \%)$ & $6(33.33 \%)$ & $16(57.14 \%)$ & $4(21.05 \%)$ & $4(11.43 \%)$ \\
Between & $2(6.45 \%)$ & $1(5.56 \%)$ & $2(7.14 \%)$ & $0(0 \%)$ & $0(0 \%)$ \\
Not Effective & $2(6.45 \%)$ & $0(0 \%)$ & $0(0 \%)$ & $3(15.79 \%)$ & $1(2.85 \%)$ \\
Not Applicable & $0(0 \%)$ & $0(0 \%)$ & $0(0 \%)$ & $0(0 \%)$ & $0(0 \%)$ \\
\hline
\end{tabular}

Table 2

Effectiveness of Methods and Media

\begin{tabular}{llllll}
\hline Effectiveness & $\mathrm{N}$ & Minimum & Maximum & Mean & \\
\hline & Statistic & Statistic & Statistic & Statistic & Std. Error \\
\hline Lecture & 31 & 1 & 5 & 3.00 & .147 \\
Video & 18 & 1 & 4 & 2.33 & .181 \\
Internet & 28 & 1 & 4 & 2.61 & .149 \\
Simulator & 19 & 1 & 5 & 2.42 & .309 \\
Aircraft & 35 & 1 & 5 & 1.57 & .155 \\
\hline
\end{tabular}

Educators were asked to respond to how the FAA's input or lack of input was affecting their ADS-B training. Themes that were discovered from educators' responses were that the FAA's lack of input had a significant effect on them not being able to train students and that more guidance from the FAA would help with their abilities to effectively teach about this new technology.

Respondents were also asked to select types of things the FAA could provide to support ADS-B training. They could select "PTS Standards," "access to training material," and "access to ADS-B equipment." Respondents also had the option to write in responses. Responses included the following: $35.3 \%(n=30)$ stated that training material provided by the FAA would help to support their ADS-B training, 27\% $(n=23)$ said access to ADS-B equipment would help, while $18.9 \%(n=16)$ said PTS Standards would be helpful. Other write-in comments suggested the FAA could provide online training materials, ADS-B simulators, and broadcast ADS-B nationwide.

Respondents were asked how important ADS-B training was to meeting the goals of their curriculums. The variables evaluated were: institutions that currently taught ADS-B versus those that did not, years worked as an aviation educator, hours of ADS-B training received, ADS-B coverage, and a comparison of the general population versus the flight instructor population. $t$-Tests were utilized for comparisons with two means, while OneWay ANOVA was used for groups with more than two means.

There was significant effect found for the perceived importance of ADS-B training between samples, $t(73)=-2.79, p<.01$ with the flight instructor group perceiving ADS- 
B training to be more important than the general sample consisting of mostly professors and administrators.

Significance was also found between perceived importance and whether educators worked in institutions that were currently teaching ADS-B, $t(73)=-3.11, p<.01$ with educators working in institutions that teach ADS-B finding the training more important. There was no significance found when comparing the perceived importance of ADS-B training to the number of years a respondent had worked as an aviation educator, $F(1,73)$ $=.44, p=.508$ or the number of hours a respondent had received ADS-B training, $F(1,60)=.15, p=.699$. There was also no significance found when comparing the perceived importance of ADS-B training to whether an educator's geographic location had ADS-B coverage, $t(73)=-1.88, p=.063$.

\section{Discussion and Conclusion}

The results of this study indicate that currently there is a minimal amount of ADS-B training taking place across the country. Some of the training that is happening appears un-standardized, sporadic, and untested. From the total sample, it was reported that the average number of hours that students were receiving ADS-B training was 19.629 hours. Earlier, it was mentioned that with three outliers removed, the average dropped dramatically to 3.06 hours of training. It is believed that the mean with the outliers removed produces a more accurate reading of the current state of ADS-B training. It is extremely unlikely that any student would receive 30, 190, or 200 hours of ADS-B instruction during their flight training. It is more likely that the respondents interpreted the question as asking how many hours their students train in an aircraft with ADS-B technology.

The same response occurred with the number of hours of ADS-B training the aviation educators stated they had received. The mean for this question was 35.88 hours with multiple outliers. With the outliers removed, the average dropped significantly to 1.8 hours. As discussed before, this would seem to be a more appropriate mean to the question. The means for these questions were reached by using the numbers from the total sample. This indicates, even with the responses from two institutions that are known to have ADS-B coverage and have roughly $92 \%$ of their aircraft equipped with ADS-B technology, that still only a small amount of time is spent educating students about this technology. When looking at the responses from the general sample, the mean drops to 0.46 hours of training. Again, due to the small size of the general sample, this number may fluctuate with future studies; it is an indication, however, that very little time is currently spent on ADS-B training.

The conclusion that only minimal training is currently taking place is also seen in the percentage of institutions that are currently teaching ADS-B technology. It was reported that of the total sample, 58.82\% were teaching ADS-B in some form. This seems to suggest that over half of all institutions are training on this new technology. However, once again, the total sample of this study includes numerous survey responses from two institutions, which are known to have ADS-B coverage and have ADS-B equipped aircraft. These institutions were also sent the survey directly instead of through the UAA 
representative. Because of this, we must look at the responses from the general sample; this group indicated that only $33.33 \%$ of the institutions are teaching ADS-B technology to its students.

This is a more accurate representation of the majority of aviation educators across the country. However, only having 15 responses in the general sample, it is likely that the percentage of institutions currently teaching ADS-B is even lower than what this study reports. Further study needs to be done in order to confirm this hypothesis, but the results of this study combined with previous research suggest this.

The educators who stated their institutions are not currently teaching ADS-B were asked if they felt their institutions were planning on teaching ADS-B in the future, and further, to explain their answers. The majority of the qualitative responses indicated that there are currently no formal plans to teach ADS-B in the future, with one of the largest reasons being a lack of equipment and coverage. Data from this study indicates that currently only $13.3 \%$ of the respondents from the general sample have ADS-B coverage in their geographic areas, with $66.7 \%$ reporting that they do not have coverage. Again, due to the small number of responses from the general survey, it is difficult to say for certain that this is an exact representation of the country, but the responses in the general survey do cover five of the nine FAA regions.

When looking at the training that is currently taking place, this study shows that the information being presented by educators was being collected from several different sources. The majority of the respondents indicated they collect material through the use of the internet or they create their own material, with only one educator indicating they use the FAA website.

Results from this study also support past research, with educators reporting that using training aircraft is the most effective way to train students on ADS-B technology. Previous research shows that, with the implementation of GPS, educators feel that handson training with the equipment is the best way for students to learn about the technology, and because of the cost of the GPS units, many educators are unable to train their students (Norton, 1997). While responses do indicate that lecture, video, internet, and FTD are also effective, training aircraft is seen as the most effective.

One of the most common trends seen in the current training responses is that the majority of the educators currently teaching ADS-B consider it to be nothing more than a traffic advisory service. They state that since there are no standards or guidelines for training, they educate their students to use ADS-B as a traffic advisory service. Only a couple of responses seem to have an understanding of what the FAA hopes the future of ADS-B will entail. Many compare ADS-B to TCAS and feel as though their students can simply learn how to use the technology through trial and error.

In this study, we compared how educators viewed the importance of ADS-B training to how many hours of ADS-B training they had received; there was no significance. The same was true when importance was compared to the number of years worked as an aviation educator. Based on past research, it was thought that those educators with more 
ADS-B training and those educators with more years working as an educator would find ADS-B training to be more important. However, with the average number of hours of ADS-B training received by the respondents being only 1.8 , it seems that more training will need to take place in order to determine if ADS-B will follow the trend of past technology such as GPS.

While there was no significance found between importance and hours of training received by educators, or importance and years worked as an educator, there was significance found between the two different sample groups. It was discovered that the flight instructor group indicated ADS-B training to be significantly more important to their curriculums than the general group sample. Because this relationship cannot be tied to more training or more time spent as a flight instructor, it is assumed that the relationship is due to more time using the ADS-B technology.

The flight instructor group consists of educators who work at institutions with ADS-B coverage and with $92 \%$ of their aircraft equipped with ADS-B technology. Because of these numbers and several qualitative responses, the study can assume that the majority of their flight time is spent in aircraft with ADS-B technology. Therefore, it is concluded that the more time someone spends using ADS-B, the more important they believe it is. These results are consistent with past studies involving technology such as GPS (Norton, 1997).

In order to further the idea that the importance of ADS-B training is increased by the amount of time an individual spends using the technology, the study compared if those educators who work in areas with ADS-B coverage feel ADS-B training is more important than those educators who work in areas that do not have coverage. This comparison was made because it seems likely that those educators training students in areas that have ADS-B coverage are more likely to be using the technology. The results of this comparison were not found to be significant; however, it is believed that a trend does occur that supports this theory, and if further research is done involving a larger number of participants, a significant result may occur.

A significant finding also occurred when the study compared educators who are currently working in institutions that teach ADS-B to educators who work in institutions that do not currently teach the new system. Results show that educators working in institutions that currently teach ADS-B believe the training is significantly more important than those who are working in institutions where no training is taking place. These results add support to the earlier findings that educators who spend more time working with ADS-B view the training in a more positive light.

ADS-B implementation seems to be following a path that was seen with earlier technologies such as GPS. According to Norton (1997), similar issues, such as the cost of GPS equipment and lack of training standards, caused the delay in the implementation of GPS. While future studies will have to be completed in order to determine how much ADS-B training is appropriate to establish proficiency, only a minimal amount of ADS-B specific training is currently taking place across the country. This study shows that the reason for this is due to a lack of ADS-B coverage, high cost of ADS-B equipment, lack 
of material, and no definable training standards or goals. Also, the training that is taking place is defining ADS-B as a traffic advisory service and allowing students to learn by trial and error.

The concern with this trend is that air traffic is projected to triple over the next several decades. NextGen is the FAA's solution to handling this traffic increase while trying to maintain the current level of aviation safety. Because of this, ADS-B implementation seems to have less flexibility then GPS, and therefore, should be approached in a more aggressive fashion.

Educators reported that traditional training methods such as lecture, videos, and Internet are effective, but it is the hands-on experience in flight simulators and training aircraft that provides the most effective training environment. Past research dealing with technically advanced aircraft supports these findings when implemented with scenario based training (Ayers, 2006). Respondents also stated that more training materials and training guidelines would allow for a more efficient approach to training students.

ADS-B is currently in the very early stages of the implementation process. A significant amount of information was gathered about current training methods and about what could be done to help improve those methods. However, as ADS-B coverage continues to increase across the country, there are many different areas that will need to be studied.

Currently, there are no training standards in place for ADS-B. In order for the FAA to implement NextGen and to reach its ultimate goal of free flight, future studies will need to be done to create effective training methods and standards. In this study, it is seen that training aircraft are rated to be the most effective training tool for ADS-B. However, it is also discussed that lack of other training options, such as simulators or classroom material, could be one of the reasons for this finding. Future research should be done to determine if an increase in training options, such as classroom material and simulators, would affect these findings.

Another area for future study is how to improve the perceived importance of ADS-B training. Currently, ADS-B is looked at as a luxury, and no real urgency exists among aviation educators. In order for ADS-B to develop in a timely manner, educators need to understand the importance that training plays in the implementation process. While this study suggests that increased exposure to the technology causes educators to view ADSB training as more important, studies should be done to determine other possible avenues to improve aviation educators' understandings of the importance of ADS-B training.

NextGen and ADS-B are the future of our air transportation system. As their implementation process continues and ADS-B coverage expands, continued studies will be necessary to insure that pilots are properly prepared for the Next Generation Air Transportation System. 


\section{References}

ADS-B Technologies, L.L.C. (2010). What is ADS-B. Retrieved from http://www.ads-b.com/home.htm

Aerospace. (2010). GPS timeline. Retrieved from http://www.aero.org/education/primers/gps/gpstimeline.html

Carney, T. Q., \& Fanjoy, R. O. (2006). Best evidence for the FAA Industry Training Standards (FITS) program for pilot training in technically advanced aircraft. Collegiate Aviation Review, 24(1), 58-66.

Casner, S. M. (2003). Learning about cockpit automation from piston trainer to modern jet transport. In Proceedings of the $12^{\text {th }}$ International Symposium on Aviation Psychology. Dayton, OH: ISAP.

Civil Aviation Safety Authority. (2006). ADS-B workbook (1 ${ }^{\text {st }}$ ed.). Canberra City, Australia: Air Services of Australia.

Craig, P. A., Bertrand, J. E., Dornan, W., Gossett, S., \& Thorsby, K. K. (2007). Scenario-based private/instrument syllabus versus traditional maneuver-based syllabi: A preliminary descriptive analysis. Collegiate Aviation Review, 23(1), $17-$ 23.

Dornan, W. A., Beckman, W., Gossett, S., \& Craig, P. A. (2007). A FITS scenariobased training program enhances GPS pilot proficiency in the general aviation pilot. Collegiate Aviation Review, 25(1), 19-27.

Federal Aviation Administration. (2010a). Automatic Dependent Surveillance Broadcast System. Retrieved from http://www.faa.gov/air_traffic/technology/ads$\mathrm{b} /$

Federal Aviation Administration. (2010b). The next generation air transportation system. Retrieved from http://www.faa.gov/about/initiatives/nextgen/defined/

Federal Aviation Administration. (2012). Next generation implementation plan. Retrieved from http://www.faa.gov/nextgen/slides/?slide=10

Fero, D. (2000). The impact of human factors on airborne separation assurance systems (ASAS). In Proceedings of the $3^{\text {rd }}$ USA/Europe Air Traffic Management $R \& D$ Seminar. Napoli: ATIO.

Fiduccia, P. (2003). General aviation technology advanced aircraft FAA-industry safety study, Final Report. Retrieved from http://www.faa.gov/training_testing/training/fits/research/media/TAA\%20Final\% 20Report.pdf 
Hilburn, B. G., Bakker, M. W. P., Pekela, W. D., \& Parasuraman, R. (1997). The effect of free flight on air traffic controller mental workload, monitoring and system performance. In Proceedings of the 10th International CEAS Conference on Free Flight (pp. 14-1/14-12). Amsterdam: CEAS.

ITT Corporation. (2010). NextGen and ADS-B: How it works and why we need it. Retrieved from http://www.itt.com/ADSB/nextgen.html

Martin, L. Using ADS-B at UND to conduct advanced navigation research in helicopter training program [Power Point slides]. Retrieved from http://www.google.com/search?sourceid=navclient\&ie=UTF8\&rlz=1T4SUNA_e nUS269US331\&q=ADS-B+UND+Martin

Mozdzanowska, A. L., Weibel, E. L., Lester, E., Hamnsman, J. R., Weigel, A., \& Marais, K. (2007). Dynamics of Air Transportation System transition and implications for ADS-B equipage. In Proceedings of the 7th AIAA Aviation Technology, Integration and Operations Conference. Belfast, Northern Ireland: ATIO.

Norton, D. (1997). A lawyer-flight instructors prognostications on the implementation of free flight: How will the large-scale of GPS into the general aviation cockpits affect the liabilities that face pilots and the flight instructors who train them? Journal of Air Law Commerce, 62.

Universal Aviation Association. (2008). Collegiate aviation guide. Auburn, AL: Author.

Williams, K., Yost, A., Holland, J., \& Tyler, R. (2002, December) Assessment of advanced cockpit displays for general aviation aircraft - The capstone program. Springfield, VA: National Technical Information Service.

Young, P., \& Fanjoy, R. (2002). Glass cockpit technology training: How is it addressed in collegiate flight programs. Collegiate Aviation Review, 20(1), 85-94.

Young, P., \& Fanjoy, R. (2003). Advanced collegiate flight automation training: What is needed and at what cost. International Journal of Applied Aviation Studies, 3(2), 215-225. 